\section{Cureus}

Received 09/24/2015

Review began 09/29/2015

Review ended 05/17/2016

Published 05/23/2016

(C) Copyright 2016

Drazin et al. This is an open access

article distributed under the terms of the Creative Commons Attribution License CC-BY 3.0., which permits unrestricted use, distribution, and reproduction in any medium, provided the original author and source are credited.

\title{
Treatment of Recurrent Disc Herniation: A Systematic Review
}

\author{
Doniel Drazin ${ }^{1}$, Beatrice Ugiliweneza ${ }^{2}$, Lutfi Al-Khouja ${ }^{1}$, Dongyan Yang ${ }^{3}$, Patrick Johnson ${ }^{1}$, \\ Terrence Kim ${ }^{4}$, Maxwell Boakye ${ }^{5}$

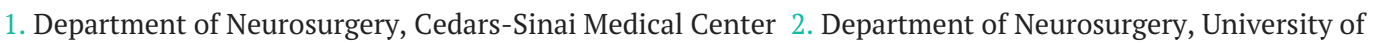 \\ Louisville, Louisville, USA 3. Department of Epidemiology and Population Health, University of Louisville 4. \\ Deparment of Orthopedics, Cedars-Sinai Medical Center 5. Department of Neurosurgery, University of \\ Louisville
}

$\square$ Corresponding author: Doniel Drazin, ddrazin@gmail.com

Disclosures can be found in Additional Information at the end of the article

\section{Abstract}

Intervertebral disc herniation is one of the most common causes of back and extremity pain. The most commonly used surgical treatment is lumbar discectomy. About $0.5-25 \%$ go on to develop recurrent disc herniation (rDH) after a successful first discectomy. Currently, there aren't any guidelines to assist surgeons in determining which approach is most appropriate to treat $\mathrm{rDH}$. A recent survey showed significant heterogeneity among surgeons regarding treatment options for $\mathrm{rDH}$. It remains unclear which methods lead to better outcomes, as there are no comparative studies with a sufficient level of evidence. In this study, we aimed to perform a systematic review to compare treatment options for $\mathrm{rDH}$ and determine if one intervention provides better outcomes than the other; more specifically, whether outcome differences exist between discectomy alone and discectomy with fusion.

We applied the PICOS (participants, intervention, comparison, outcome, study design) format to develop this systematic review through PubMed. Twenty-seven papers from 1978-2014 met our inclusion criteria and were included in the analysis. Nine papers reported outcomes after discectomy and seven of them showed good or excellent outcomes (70.60\%-89\%). Ten papers reported on minimally invasive discectomy. The percent change in visual analog scale (VAS) ranged from $-50.77 \%$ to $-86.57 \%$, indicating an overall pain reduction. Four studies out of the ten reported good or excellent outcomes (81\% to $90.2 \%$ ). Three studies looked at posterolateral fusion. Three studies analyzed posterior lumbar interbody fusion. For one study, we found the VAS percentage change to be $-46.02 \%$. All reported good to excellent outcomes. Six studies evaluated the transforaminal lumbar interbody fusion. All reported improvement in pain. Four used VAS, and we found the percent change to be $-54 \%$ to $-86.5 \%$. The other two used the Japanese Orthopedic Association (JOA) score, and we found the percent change to be $68.3 \%$ to 93.3\%.

We did not find enough evidence to support any significant difference in outcomes between discectomy alone and discectomy with fusion. The limitation of our study includes the lack of standardized outcomes reporting in the literature. However, reviewing the selected articles shows that fusion may have a greater improvement in pain compared to reoperation without fusion. Nonetheless, our study shows that further and more in-depth investigation is needed on the of treatment of $\mathrm{rDH}$.

Categories: Neurosurgery

Keywords: recurrent disc herniation, recurrent lumbar disc herniation, spine, spinal fusion, revision fusion, minimally invasive lumbar fusion, interbody fusion, back pain 


\section{Introduction}

Intervertebral disc herniation is one of the most common causes of back and extremity pain that can eventually require surgical intervention. Many surgical approaches have been utilized to treat disc herniation where the type of surgery is dependent upon the level of herniation, type of herniation, symptomatology, and surgeon preference. The most commonly used surgical method is a lumbar discectomy [1].

Disc reherniation is the most common cause of reoperation after primary disc surgery and is defined as disc herniation occurring at the same level in a patient after a definite pain-free period of at least six months from initial surgery [2]. Rates of recurrent disc herniation ( $\mathrm{rDH})$ have been reported to be between $0.5 \%$ and $25 \%$ [3]. Although there are many theories as to what increases a patient's chance for reherniation, no one factor has been identified consistently in the literature. Some of these proposed risk factors include obesity, smoking, male gender, diabetes, weightlifting, the size of the annular tear, and type of primary operation [4-17]. Other causes of reoperation include new disc herniation at a different level, epidural fibrosis, adhesive arachnoiditis, spinal stenosis, and segmental instability [18].

Currently, there are no guidelines or significant comparative studies to assist surgeons in determining which approach would be most appropriate to treat $\mathrm{rDH}$. The American Association of Neurologic Surgeons (AANS) 2014 guidelines report low-level evidence to support fusion for rDH and call for further investigations with improved study designs to better address this issue [19]. In the absence of guidelines to approach patients with $\mathrm{rDH}$, there are significant differences in treatment plans among spine surgeons in the United States, which was evaluated in a survey of spine surgeons by Mroz, et al. [20]. Their survey found that a patient's treatment plan varied based on surgeon experience and operative volume. With the prognosis of repeated back surgery being relatively poor in regards to pain relief and return to work [21], identifying the appropriate treatment for recurrent disc herniation is important to improve prognosis. A recent recommendation by Wang, et al. is to perform a discectomy in patients with $\mathrm{rDH}$ and radiculopathy [19]. Fu, et al. reported similar recommendations. Additionally, fusion has been recommended if the patient has associated lumbar instability, radiographic degenerative changes, and/or chronic axial lower back pain [22]. However, a repeat discectomy is generally more difficult due to scar tissue from the primary surgery, and there is an increased the risk of dural tears or nerve injury [23]. Furthermore, using a minimally invasive percutaneous endoscopic method was determined to be effective in decreasing the chance of fusion and bleeding with reoperation in comparison to conventional revision discectomy [23]. A retrospective study by Ambrossi, et al. found a substantial amount of healthcare costs associated with recurrent disc herniation averaging \$26,593 per patient to diagnose and manage [24]. All in all, it is still unclear which method has shown to be more effective for reoperation.

There are currently no studies directly comparing the various treatments of rDHs. The goal of this systematic review is to compare the various treatment options for $\mathrm{rDH}$ and determine if one intervention provides better outcomes than the others. More specifically, if there is a difference in outcomes from surgery with and without fusion.

The PICOS format is a technique used to help formulate a clinical question and guide the subsequent literature search to provide an evidence-based technique to acquire clinical information from the literature [25-26]. Applying the PICOS format in developing this systematic review, we established the following criteria:

- Participants: Adults $\geqslant 18$ with recurrent disc herniation

- Interventions: discectomy, minimally invasive surgical (MIS) discectomy, posterolateral fusion (PLF), posterior lumbar interbody fusion (PLIF), transforaminal interbody fusion (TLIF), anterior lumbar interbody fusion (ALIF) 
- Comparisons: discectomy, MIS discectomy, PLF, PLIF, TLIF, ALIF

- Outcomes: any

- Study Designs: any

The hope is that this study, with the above criteria, will help to determine the advantages and disadvantages of various interventions to treat $\mathrm{rDH}$.

\section{Materials And Methods}

\section{Literature search}

A literature search was performed using PubMed with the search term "recurrent disc herniation" with MeSH terms "intervertebral disc displacement", "reoperation", and "recurrence”. The search was performed on June 5, 2015. Studies were excluded if they did not address the treatment of recurrent disc herniation, did not state the specific intervention being studied, did not report validated outcomes of that specific intervention, or did not have an adequate sample size (which was arbitrarily determined to be $\geqslant 10$ patients per study group). No preference was taken to the type of study (prospective, retrospective, etc.), the length of follow-up, or status of publication. Ultimately, we included papers that had covered a specific surgical treatment option for recurrent lumbar disc herniation that reported the outcomes of the intervention from different studies with an adequate sample size. We first reviewed the abstracts of all the articles that populated following the search for inclusion and exclusion criteria. Then, an in-depth review of each individual article was conducted for further inclusion into our analysis.

\section{Data variables}

While reading through each paper, we looked at the type of surgery used, study type, length of follow-up, time spent in the operating room, estimated blood loss, costs associated with reoperation, visual analogue scale ratings (VAS, pre- and postoperatively), Oswestry Disability Index (ODI, pre- and postoperatively), length of stay (LOS), re-operation outcomes, complications with re-operation, and percent with good or excellent outcomes. Percent differences of preoperative and postoperative VAS and ODI were calculated by dividing the difference over the preoperative score:

$$
\begin{aligned}
& \text { PercentDifferenceVASorODI }=\frac{\text { PreoperativeVASorODI }- \text { PostoperativeVASorODI }}{\text { PreoperativeVASorODI }} \times 100 \\
& \text { PercentDifferenceJOA }=\frac{\text { PostoperativeJOA }- \text { PreoperativeJOA }}{\text { PostoperativeJOA }} \times 100
\end{aligned}
$$

In calculating the percent difference in VAS and ODI, we were able to establish an internal control for each study and more accurately present the average changes in subjective and objective outcomes after surgery rather than comparing the raw numbers from each study.

\section{Results}

Using the queries listed above, a search through PubMed resulted in 106 abstracts that met initial screening criteria. Careful analysis of these 106 articles brought us to 27 that fit the inclusion criteria to be part of the analysis. Of note, some of these 27 articles discussed more than one type of surgery. There were eight articles studying repeat surgery with fusion, 17 without fusion, and two studying both. A summary of these papers is listed is listed in Tables 1-2. 


\section{Cureus}

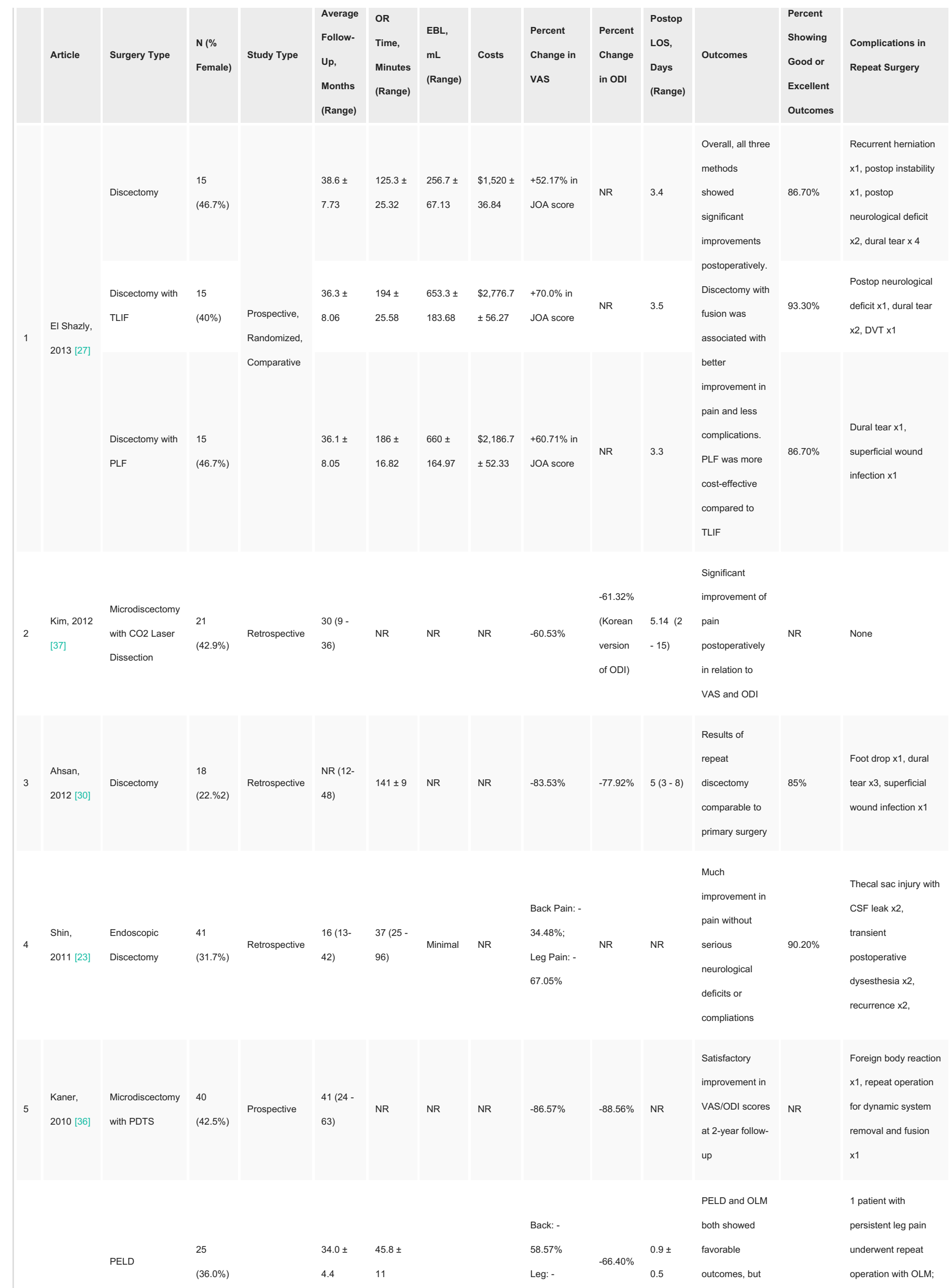




\section{Cureus}

Lee, 2009

[39]

Kim, 2009
Retrospective

NR

NR

$\begin{array}{llll}\text { Open Lumbar } & 29 & 34.6 \pm & 73.8 \pm \\ \text { Microdiscectomy } & (24.1 \%) & 4.6 & 25.7\end{array}$

Microdiscectomy 14 (21.4\%)
Retrospective

56
$65.48 \%$

Back:-

$42.59 \%$

Leg: -

$59.30 \%$

$-71.16 \% \quad 3.8=$

$-71.16 \% \quad 1.4$

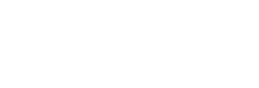

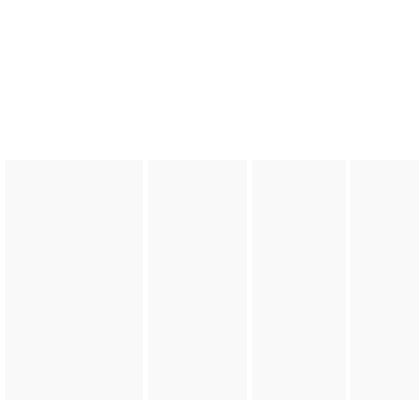

Conservative 6

$\$ 2,315$

Ambrossi,

2009 [24]

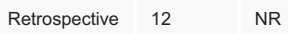

Discectomy $\quad 11$

Guo, Discectomy by 51

2009 [29]

Fenestration

(25.5\%)

Retrospective 146.8

NR

R
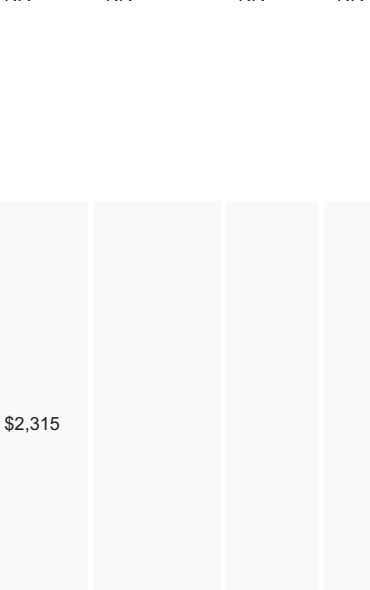

NR

$+64.8 \%$ in
JOA score

(1)

1 patient witho

symptom relief

after surgery

who

subsequently

underwent

fusion

8 patients

(15.7\%) failed

revision open

lumbar

$70.60 \%$

5 dural tears, 2 nerve

root injuries, and 1

discectomy by

deep infection

fenestration

Overall longer

OR time for

reoperation

$89 \%$

compared to

(compared

primary surgery

to $95 \%$

after

(110 vs. 75 ) and

an unsuccessful

primary

surgery rate of

operation)

$2 \%$

Average

improvement of

10 patients with 


\section{Cureus}

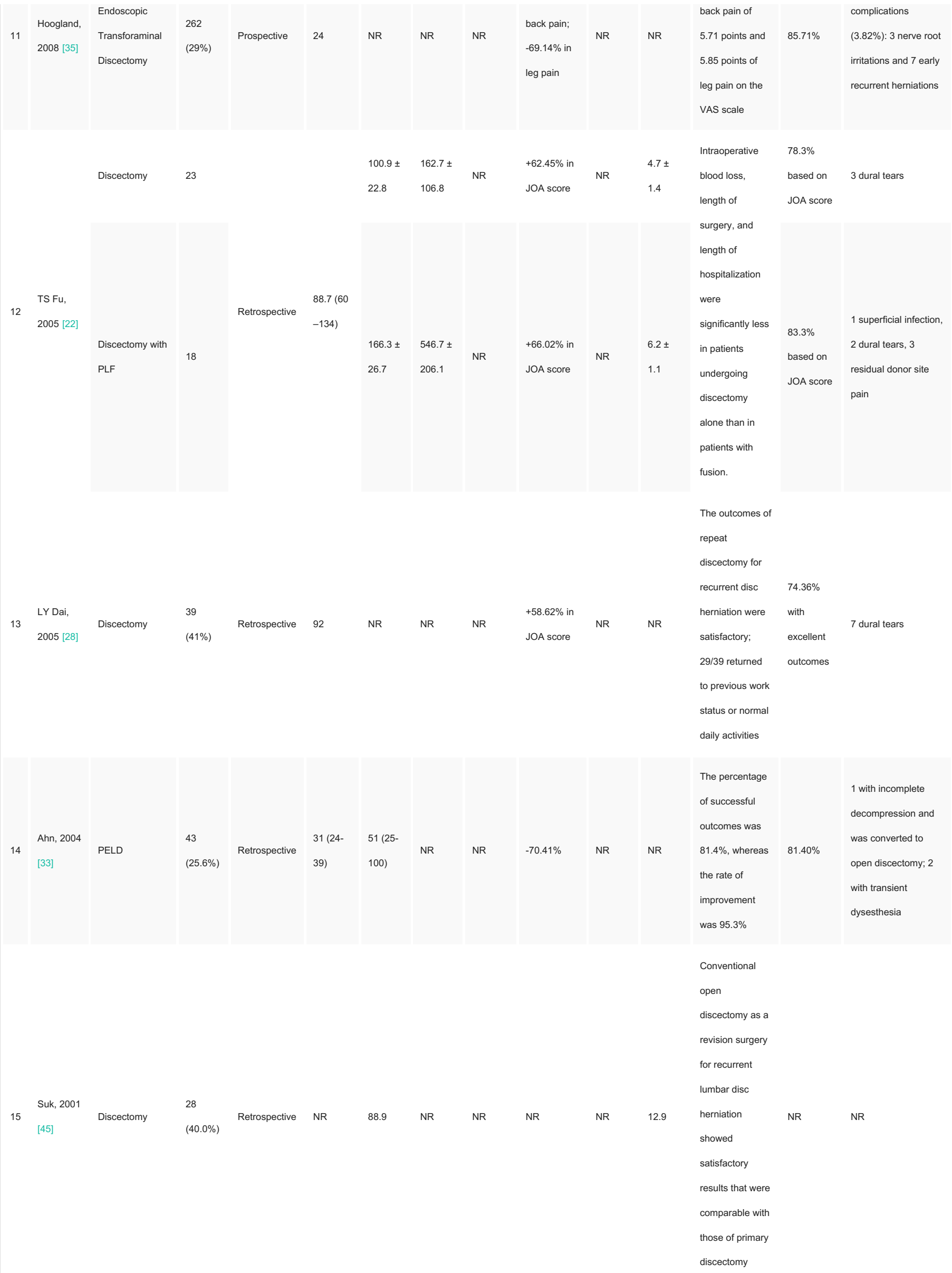




\section{Cureus}

\begin{tabular}{|c|c|c|c|c|c|c|c|c|c|c|c|c|c|c|}
\hline 16 & $\begin{array}{l}\text { Cinotti, } \\
1998 \text { [34] }\end{array}$ & Microdiscectomy & $\begin{array}{l}26 \\
(31.0 \%)\end{array}$ & Prospective & $\begin{array}{l}24 \\
\text { months }\end{array}$ & NR & NR & NR & UTD & NR & $1.5(1-3)$ & $\begin{array}{l}17 \text { patients were } \\
\text { able to return to } \\
\text { full employment } \\
\text { and } 4 \text { were able } \\
\text { to return to } \\
\text { regular daily } \\
\text { activities at } \\
\text { same level as } \\
\text { prior to primary } \\
\text { discectomy }\end{array}$ & $81 \%$ & $\begin{array}{l}2 \text { dural tears, } 1 \text { with } \\
\text { postop discitis, } 1 \text { with } \\
\text { second recurrent } \\
\text { herniation }\end{array}$ \\
\hline 17 & $\begin{array}{l}\text { Silvers, } \\
1994 \text { [40] }\end{array}$ & Microdiscectomy & $\begin{array}{l}82 \\
(35.0 \%)\end{array}$ & Retrospective & $\begin{array}{l}46.8(< \\
12-168)\end{array}$ & NR & NR & NR & NR & NR & 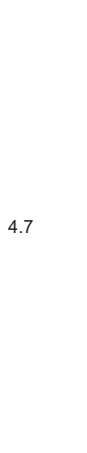 & $\begin{array}{l}\text { Patients who } \\
\text { presented within } \\
\text { one year of } \\
\text { primary surgery } \\
\text { with same level } \\
\text { and same side } \\
\text { recurrence had } \\
\text { poor outcomes } \\
\text { following } \\
\text { microdiscectomy }\end{array}$ & NR & $\begin{array}{l}\text { } 10 \text { dural tears ( } 4 \text { with } \\
\text { CSF leakage), } 6 \\
\text { wound infections, } 2 \\
\text { pseudomeningoceles, } \\
1 \text { wound hematoma }\end{array}$ \\
\hline 18 & $\begin{array}{l}\text { Herron, } \\
1994 \text { [31] }\end{array}$ & $\begin{array}{l}\text { Laminectomy } \\
\text { and Discectomy }\end{array}$ & 46 & Retrospective & $\begin{array}{l}54(12- \\
128)\end{array}$ & NR & NR & NR & NR & NR & NR & $\begin{array}{l}\text { Satisfactory } \\
\text { outcomes in } \\
\text { treatment of } \\
\text { rLDH without } \\
\text { associated } \\
\text { spinal instability. } \\
\text { Most patients } \\
\text { experienced } \\
\text { "good" surgical } \\
\text { outcomes with } \\
>75 \% \text { relief in } \\
\text { back and leg } \\
\text { pain }\end{array}$ & $\begin{array}{l}>75 \% \text { with } \\
\text { good } \\
\text { surgical } \\
\text { outcomes }\end{array}$ & NR \\
\hline 19 & $\begin{array}{l}\text { Hou, } \\
2015 \text { [46] }\end{array}$ & $\begin{array}{l}\text { Repeat } \\
\text { Microendoscopic } \\
\text { Discectomy }\end{array}$ & $\begin{array}{l}25 \\
(52 \%)\end{array}$ & Prospective & $\begin{array}{l}36(12- \\
72)\end{array}$ & $\begin{array}{l}85(60- \\
100)\end{array}$ & $\begin{array}{l}68(20- \\
100)\end{array}$ & NR & $\begin{array}{l}\text { Leg Pain: - } \\
71.6 \%\end{array}$ & $-54.80 \%$ & NR & $\begin{array}{l}\text { No nerve root or } \\
\text { cauda equina } \\
\text { injury }\end{array}$ & $96 \%$ & $\begin{array}{l}\text { Small dural tear } x 3 \text {, } \\
\text { Recurrence } x 1 \\
\text { resulting in fusion }\end{array}$ \\
\hline
\end{tabular}

\section{TABLE 1: Treatment of Recurrent Disc Herniation without Spinal Fusion Studies}

EBL: Estimated Blood Loss; VAS: Visual Analog Scale; ODI: Oswestry Disability Index; LOS: Length of Stay; TLIF: Transforaminal Interbody Fusion; DVT: Deep Vein Thrombosis; PLF: Posterior Lumbar Fusion; JOA: Japanese Orthopedic Association; NR: Not Reported; CSF: Cerebrospinal Fluid; PDTS: Posterior Dynamic Transpedicular Stabilisation; PELD: Percutaneous Endoscopic Lumbar Discectomy; OLM: Open Lumbar Discectomy

\begin{tabular}{|c|c|c|c|c|c|c|c|c|c|c|c|c|c|}
\hline Article & Surgery Type & $\begin{array}{l}\mathrm{N}(\% \\
\text { Female) }\end{array}$ & Study Type & $\begin{array}{l}\text { Average } \\
\text { Follow- } \\
\text { Up, } \\
\text { Months }\end{array}$ & $\begin{array}{l}\text { OR } \\
\text { Time, } \\
\text { Minutes } \\
\text { (Range) }\end{array}$ & $\begin{array}{l}\text { EBL, } \\
\mathrm{mL} \\
\text { (Range) }\end{array}$ & Costs & $\begin{array}{l}\text { Percent } \\
\text { Change } \\
\text { in VAS }\end{array}$ & $\begin{array}{l}\text { Percent } \\
\text { Change } \\
\text { in ODI }\end{array}$ & $\begin{array}{l}\text { Postop } \\
\text { LOS, } \\
\text { Days } \\
\text { (Range) }\end{array}$ & Outcomes & $\begin{array}{l}\text { Percent } \\
\text { Showing } \\
\text { Good or } \\
\text { Excellent }\end{array}$ & $\begin{array}{l}\text { Complications } \\
\text { in Repeat } \\
\text { Surgery }\end{array}$ \\
\hline
\end{tabular}




\section{Cureus}

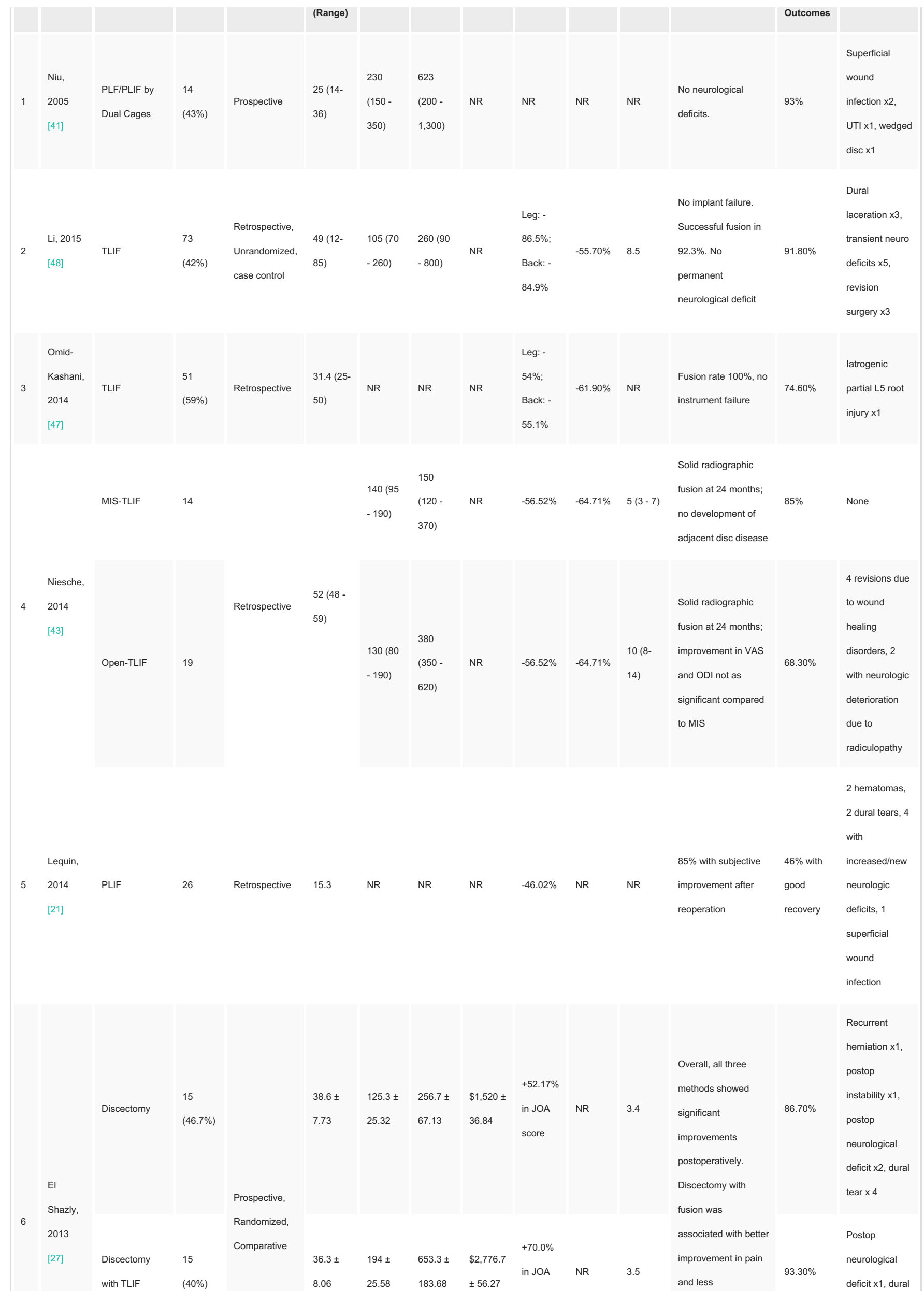




\section{Cureus}

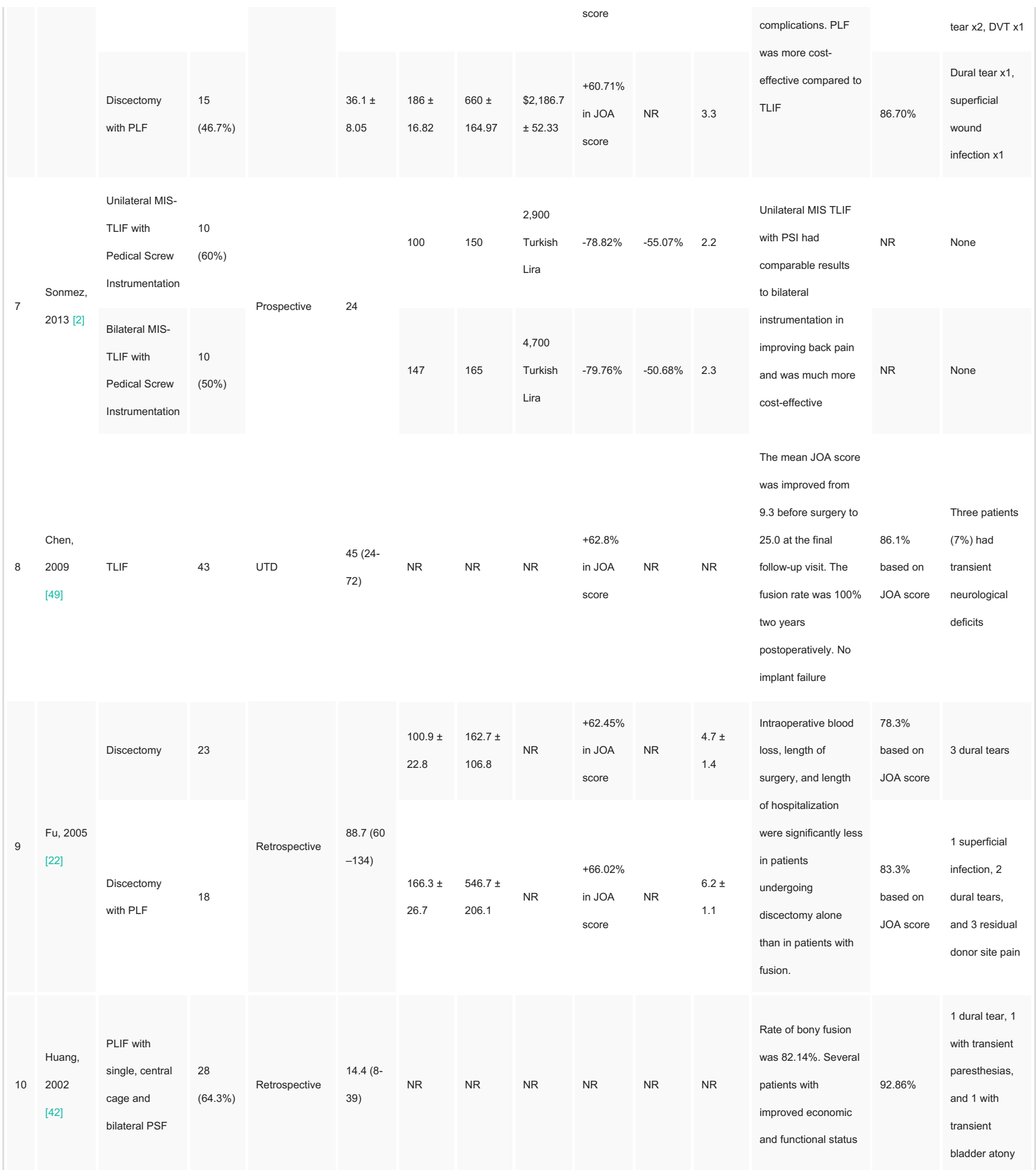

\section{TABLE 2: Treatment of Recurrent Disc Herniation with Spinal Fusion Studies}

EBL: Estimated Blood Loss; VAS: Visual Analog Scale; ODI: Oswestry Disability Index; LOS: Length of Stay; PLF: Posterior Lumbar Fusion; PLIF: Posterior Lumbar Interbody Fusion; NR: Not Reported; UTI: Urinary Tract Infection; TLIF: Transforaminal Lumbar Interbody Fusion; MIS: Minimally Invasive Surgery; DVT: Deep Vein Thrombosis; JOA: Japanese Orthopedic Association; PSI: Pedicle Screw Instrumentation; UTD: Unable to Determine; PSF: Posterior Spinal Fusion 


\section{Cureus}

Of the 27 articles reviewed for analysis, seven discussed outcomes from discectomy, 10 from a minimally invasive discectomy, five from TLIF, two from PLIF, one from both PLF/PLIF, and two comparative studies comparing discectomy and discectomy with fusion (Figures 1-2) [22, 27]. Six of the twenty-seven articles either had a follow-up time $<24$ months or were not reported; the other 21 articles had at least a 24-month follow-up. There were seven prospective studies (26\%), 19 retrospective studies (70\%), and one where we were unable to determine whether it was a prospective or retrospective study.

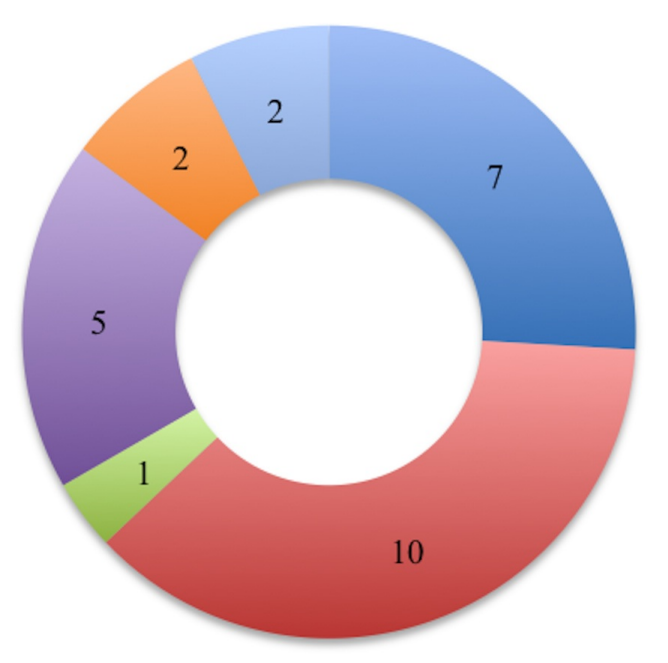

Discectomy

MIS Discectomy

PLF/PLIF

- Transforaminal Lumbar Interbody Fusion

- ALIF

$\square$ PLIF

Comparative Studies

\section{FIGURE 1: Number of Papers by Type of Surgery}

MIS: Minimally Invasive Surgery, PLF: Posterior Lumbar Fusion, PLIF: Posterior Lumbar Interbody Fusion, ALIF: Anterior Lumbar Interbody Fusion

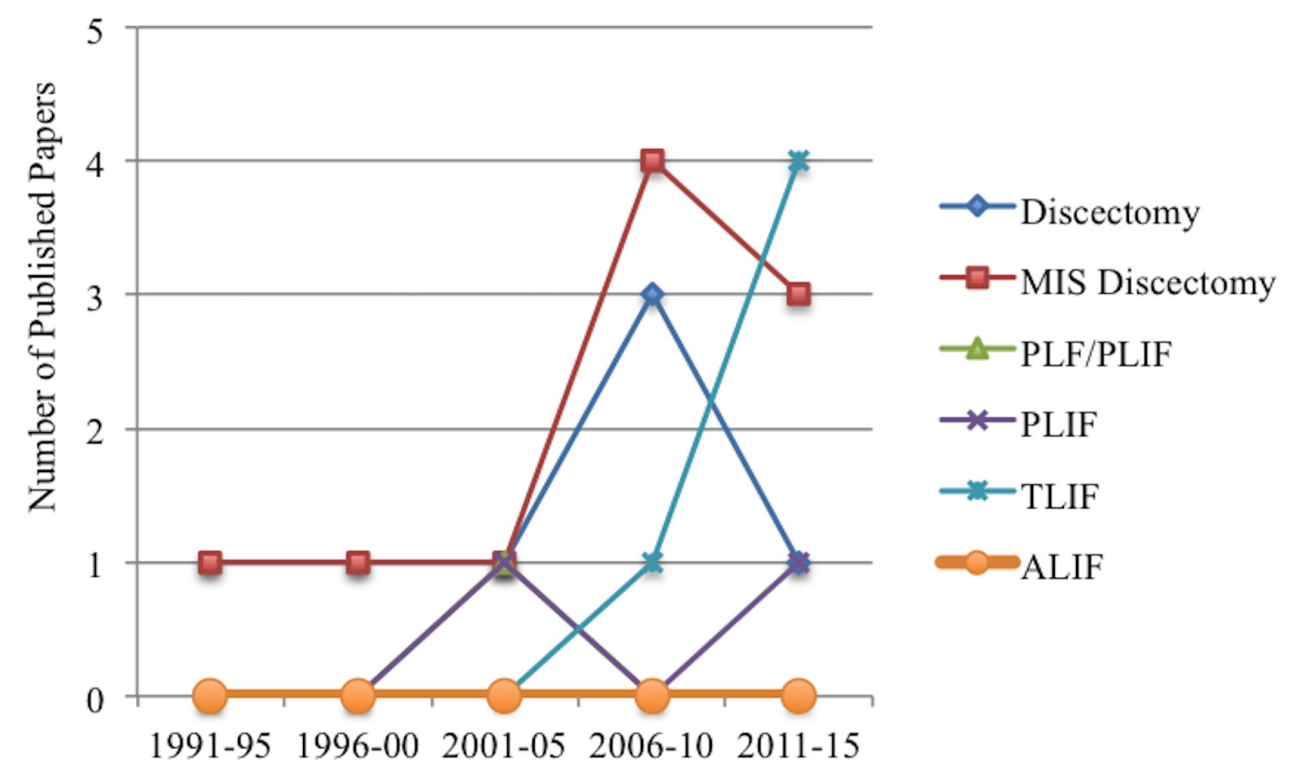

FIGURE 2: Number of Papers by Type of Surgery and Year of 


\section{Publication}

MIS: Minimally Invasive Surgery, PLF: Posterior Lumbar Fusion, PLIF: Posterior Lumbar Interbody Fusion, TLIF: Transforaminal Lumbar Interbody Fusion, ALIF: Anterior Lumbar Interbody Fusion

\section{Discectomy}

Of the nine articles reporting on the outcomes of discectomy for $\mathrm{rDH}$, five (55.5\%) reported VAS, JOA, or ODI scores for their study population. Of the five that did report these variables, four were on the JOA scale, which is a modified ODI [22, 27-29]. The percent improvement in JOA among these studies ranged from $52.17 \%$ to $64.8 \%$. Only one study reported ODI scores [30]. As a result, no accurate calculations can be made to determine the average VAS and ODI changes after discectomy for $\mathrm{rDH}$. Seven of the nine studies reported the percentage of patients showing good or excellent outcomes, which ranged from $70.60 \%$ to $89 \%$ [29, 31-32]. Of the total 326 patients undergoing discectomy from nine studies, dural tear was the most common complication reported occurring in 26 patients (8\%) with three studies not reporting on complications. One reherniation occurred in $0.3 \%$ [27]. Neurological deficits or nerve root injuries occurred in five patients (1.5\%).

\section{Minimally invasive discectomy}

Of the ten articles reporting on the outcomes of minimally invasive discectomy for rDH, six (60\%) reported VAS and four (40\%) reported ODI. Percent improvement in VAS among these studies ranged from $50.77 \%$ to $86.57 \%$, indicating an overall pain reduction after operation for $\mathrm{rDH}$ using a minimally invasive discectomy. Percent improvement in ODI ranged from $61.32 \%$ to $88.56 \%$ (based on preoperative and postoperative values). Four of the nine studies reported the percentage of patients showing good or excellent outcomes, which ranged from $81 \%$ to $90.2 \%$ [23, 33-40]. Of the total 579 patients undergoing minimally invasive discectomy, dural tear was the most common complication reported and occurred in 23 patients (4\%). Twelve patients had reherniation (2\%). One of the 10 articles reviewed did not report on complications [38]. Neurological complications occurred in seven patients (1.2\%): four with transient dysesthesia and three with nerve root irritations.

\section{Posterolateral fusion (PLF)}

Three studies were noted to have evaluated patients undergoing PLF after rDH. One of these studies performed PLIF in 12 of the 14 patients evaluated, so it was instead excluded from this category [39]. The two remaining studies analyzed the PLF treatment in rDH and reported back pain based on the JOA scale, showing an improvement by $60.71 \%$ and $66.02 \%$ [22, 27]. El Shazly, et al. and $\mathrm{Fu}$, et al. reported good or excellent outcomes in $86.70 \%$ and $83.3 \%$, respectively. El Shazly, et al. also found PLF to be more cost effective than TLIF, but patients undergoing TLIF had a better improvement in JOA score ( $70 \%$ vs. $60.7 \%$, respectively) and a larger percentage showing either good or excellent outcomes ( $93.3 \%$ vs. 86.7\%). Fu, et al. found much longer OR times and larger EBL with PLF compared to discectomy alone but, overall, showed better outcomes with PLF. Of the 33 patients from the two studies who underwent PLF, three patients had dural tears (9\%) and two had superficial wound infections (6\%).

\section{Posterior lumbar interbody fusion (PLIF)}

One of the three studies analyzed reported preoperative and postoperative VAS with a percent improvement of $46.02 \%$ [21]. Lequin, et al. reported $46 \%$ with good outcomes, Huang, et al. reported $92.86 \%$ with good or excellent outcomes, and $\mathrm{Niu}$, et al. reported $93 \%$ with good or excellent outcomes [21, 41-42]. There were 68 patients who underwent PLIF between the three studies reviewed. Three patients had dural tears (4.4\%) and six patients had neurological complications (8.8\%). The neurological complications included worsening or new neurological 
deficits in four patients, one patient with transient paresthesias, and one patient with bladder atony.

\section{Transforaminal lumbar interbody fusion (TLIF)}

Four of the six studies used the VAS metric to assess pain while the other two utilized the JOA scale. VAS improvement ranged from $54 \%$ to $86.5 \%$. JOA scale change improvement was reported from $62.8 \%$ to $70 \%$. Percent showing good or excellent outcomes ranged from $68.3 \%$ to $93.3 \%$ in the five studies reporting these findings. Niesche, et al. found no complications utilizing a minimally invasive TLIF approach with $85 \%$ showing good or excellent outcomes [43]. There were 216 patients who underwent TLIF from the six studies reviewed. Five patients (2.3\%) had dural tears, 10 with neurological deficits postoperatively (4.6\%), and three requiring revision surgery (1.3\%).

\section{Discussion}

In reviewing the 23 articles that reported treatment outcomes for $\mathrm{rDH}$, it is still difficult to ascertain which intervention is the most appropriate to use. All of the papers showed overall positive results in relieving pain when comparing preoperative and postoperative functional outcome measures, such as the VAS, JOA, and ODI. VAS and ODI are currently the most valuable resources of objective data in measuring the level of success. It is difficult, however, to identify any objective measures of success through radiographic imaging. A study by Cheng, et al. looked at the rate of first-time recurrent herniations in 207 patients based on the type of primary surgery and found that there was a lower rate of recurrence using a traditional open approach versus a microendoscopic discectomy or percutaneous endoscopic discectomy (37.8\% vs. 47.1\% and 70.6\%, respectively) [44]. There is an insufficient amount of published data to help determine the most appropriate method of treating $\mathrm{rDH}$ at this time. Being that disc herniation is one of the most common back problems requiring surgical intervention, identifying the appropriate methods to accurately diagnose and treat $\mathrm{rDH}$ with standard outcomes measures would be worthwhile to investigate. This would also help to establish the most cost-effective intervention (surgical and non-surgical) with the lowest associated morbidity.

The choice between repeat discectomy and discectomy with fusion for rDH has been a highly debated topic [45-49]. In one perspective, fusion is usually costlier, associated with more complications, longer OR times, larger EBL, and longer hospitalizations. In the analysis performed here, it seems that TLIF is the more superior fusion option based on the greatest decrease in VAS/ODI compared to the other fusion studies reviewed. However, the lack of published data on other forms of fusion and limited comparative studies makes it more difficult to accurately make this conclusion. One of the two comparative studies reviewed by Fu, et al. compared discectomy and discectomy with PLF and found better improvement of pain after fusion. However, fusion was also associated with more complications, more blood loss, and longer operative times compared with discectomy alone [22].

From a surgical decision-making perspective, it was difficult to determine indications or a reliable algorithm for selection of fusion for $\mathrm{rDH}$ from the articles reviewed. Mroz, et al. published their findings from a survey identifying the surgical treatment patterns among spine surgeons in the United States for lumbar rDH and found that the number of surgeries performed and years of practice had a statistically significant impact on the type of surgery performed [20]. They concluded that a surgeon practicing for 15-20 years is less likely to perform a revision microdiscectomy with fusion versus revision microdiscectomy alone. However, they also found that higher volume surgeons with > 200 cases per year were more likely to perform a fusion to address $\mathrm{rDH}$. This variance could be indicative of multiple factors, including surgeon preference and patient characteristics, but we need to consider the lack of proper evidence-based data as a probable reason for the lack of definitive recommendations. One consideration is to utilize the National Neurosurgery Quality and Outcomes Database $\left(\mathrm{N}^{2} \mathrm{QOD}\right)$ registry, which is a 
prospectively collected sampling of patients who experienced same-level, same-side $\mathrm{rDH}$, had either a discectomy or arthrodesis, and had one-year follow-up [50]. This registry collects the same data variables on all patients, which allows for better statistical analysis than when trying to combine data in a meta-analysis. Additionally, this will assist in performing more accurate comparative analyses to determine indications or generate a reliable algorithm for the treatment of $\mathrm{rDH}$. The abstract by McGirt, et al. found greater healthcare utilization and morbidity with arthrodesis in their comparative analysis of 417 patients in the N2QOD registry and concluded that revision discectomy is the more efficient treatment option [50].

In regards to reporting the rates of reherniation, one concern in the literature is the lack of distinguishability between radiographic evidence of reherniation and symptomatic reherniation. Lebow, et al. found that about one-fourth of patients who underwent a lumbar discectomy had radiographic evidence of reherniation with the majority being asymptomatic [51]. Furthermore, these asymptomatic reherniations did not develop any clinical consequences at the two-year follow-up. In regards to the studies reviewed in this analysis, it is unclear whether they had radiographic or symptomatic evidence of reherniation. For example, Vik, et al. reported outcomes on 39 patients who underwent revision surgery due to suspected herniation but then found that recurrence had been found in only 14 of them [52]. Similarly, Ozgen, et al. studied 114 patients with previous lumbar disc surgery who underwent re-exploration and found that only 56 had a true recurrence of herniation [18]. Epidural fibrosis, a major intraoperative finding in non-rDH revision surgeries, is often difficult to distinguish with advanced imaging and presents with similar clinical symptomology. This has been shown in previously published studies to be associated with poor results from revision surgical intervention [53-57]. It appears from these reported data that many patients who do not have a true recurrence are still undergoing surgical treatment in place of a more conservative management without the morbidity of a second operation. Formulating a more concrete set of diagnostic criteria for $\mathrm{rDH}$ would help delineate the use of symptomatic versus radiographic diagnosis. It would be worthwhile to perform a comparative analysis along with a cost-effectiveness analysis to determine if the costs of imaging to diagnose $\mathrm{rDH}$ outweigh the costs of unnecessary operations for patients who were incorrectly diagnosed or having clinical symptomatology alone.

In our review of the literature for the cervical and thoracic spine, the rates of $\mathrm{rDH}$ were rarely mentioned. Although the incidence of $\mathrm{rDH}$ in these spinal regions occurs less frequently compared to the lumbar spine, the management is somewhat similar. It would be of value to determine the efficacy of these various interventions to better guide our treatment algorithms.

\section{Study limitations}

Some of the limitations of this study include the small number of papers currently published on the treatment of $\mathrm{rDH}$ and the reporting of standardized outcome measures. Additionally, of the papers that were included, there was a broad spectrum of definitions of $\mathrm{rDH}$, making it difficult to compare the patients selected for treatment and their outcomes. The lack of uniformity in postoperative data collection was further amplified by not all of the studies reporting similar time points after surgery for postoperative VAS and ODI. The possible variability in when the VAS and ODI were recorded in each paper could be a limitation that we were unable to correct for, given the data reported.

\section{Future outlook/recommendations}

Future studies assessing outcomes of the treatment of recurrent disc herniation are needed in order to establish a better perspective on the proper approach to and management of recurrent disc herniation. Studies using registries can help better elucidate these questions by allowing more comparative analyses to be done and work towards making more accurate treatment recommendations and algorithms [45]. This includes further investigation of risk factors for recurrence and comparative studies on the outcomes of these surgical techniques. Identifying true risk factors for recurrent herniation can help stratify patients for different treatment options 


\section{Cureus}

and possibly have an impact on costs if reherniation can be avoided. Another consideration is the question of accurate versus precise diagnosis of recurrence. Although it is difficult right now to establish an accurate diagnosis, having a better definition of $\mathrm{rDH}$ would allow for better precision and standardization of what the literature describes as $\mathrm{rDH}$. Several of the studies reviewed noted performing MRIs on each patient to determine if reherniation had occurred, but this may not be necessary or the most cost-effective method of diagnosis and treatment.

We developed a set of recommendations for future studies on surgical outcomes, which are summarized in Table 3. In order to achieve more accurate results on the outcomes of a surgical intervention for $\mathrm{rDH}$, prospective studies with a minimum two-year follow-up are needed to properly assess the long-term implications after surgery. We hope that these factors, along with already published reporting guidelines, will help produce studies that can change the way patients are treated for $\mathrm{rDH}$ in the future.

\section{Recommendations:}

1. How recurrence of disc herniation was determined (imaging, symptomatology, etc.)

2. Which level and side (ipsilateral or contralateral) the reherniation was located

3. Time frame after primary operation

4. Which intervention(s) are being studied

4. Reporting of preoperative VAS/ODI

5. Reporting postoperative VAS/ODI immediately after surgery and at 6-month intervals for at least 2 years

6. Percent with good or excellent outcomes using MacNab's assessment

7. Complicating factors to reherniation (i.e. fibrosis, etc.)

8. Time until return to work or regular daily activities

TABLE 3: Recommendations for Future Studies in Recurrent Disc Herniation Treatment.

\section{Conclusions}

The current analysis was not able to conclude on any significant difference in outcomes in comparing one surgical method to another. This is largely based on the lack of standardized reporting of outcomes in the literature, which makes it difficult to combine these data points for analysis with such a small power. However, in reviewing the few selected articles that met our stringent criteria, we concluded that fusion may have a greater improvement in pain and functional outcomes compared to reoperation without fusion at the cost of more complications, increased blood loss, and longer operative times for the treatment of $\mathrm{rDH}$.

\section{Additional Information Disclosures}

Human subjects: All authors have confirmed that this study did not involve human participants or tissue. Animal subjects: All authors have confirmed that this study did not involve animal subjects or tissue. Conflicts of interest: In compliance with the ICMJE uniform disclosure form, all authors declare the following: Payment/services info: All authors have declared that no 
financial support was received from any organization for the submitted work. Financial relationships: All authors have declared that they have no financial relationships at present or within the previous three years with any organizations that might have an interest in the submitted work. Other relationships: All authors have declared that there are no other relationships or activities that could appear to have influenced the submitted work.

\section{References}

1. Swartz KR, Trost GR: Recurrent lumbar disc herniation. Neurosurg Focus. 2003, 15:E10. 10.3171/foc.2003.15.3.10

2. Sonmez E, Coven I, Sahinturk F, Yilmaz C, Caner H: Unilateral percutaneous pedicle screw instrumentation with minimally invasive TLIF for the treatment of recurrent lumbar disk disease: 2 years follow-up. Turk Neurosurg. 2013, 23:372-78. 10.5137/1019-5149.JTN.7122-12.1

3. Berjano P, Pejrona M, Damilano M: Microdiscectomy for recurrent L5-S1 disc herniation . Eur Spine J. 2013, 22:2915-17. 10.1007/s00586-013-3114-9

4. Fritzell P, Knutsson B, Sanden B, Strömqvist B, Hägg O: Recurrent versus primary lumbar disc herniation surgery patient-reported outcomes in the Swedish Spine Register Swespine. Clin Orthop Relat Res. 2015, 473:1978-84. 10.1007/s11999-014-3596-8

5. Kim JM, Lee SH, Ahn Y, Yoon DH, Lee CD, Lim ST: Recurrence after successful percutaneous endoscopic lumbar discectomy. Minim Invasive Neurosurg. 2007, 50:82-85. 10.1055/s-2007982504

6. McGirt MJ, Ambrossi GL, Datoo G, Sciubba DM, Witham TF, Wolinsky JP, Gokaslan ZL, Bydon A: Recurrent disc herniation and long-term back pain after primary lumbar discectomy: review of outcomes reported for limited versus aggressive disc removal. Neurosurgery. 2009, 64:338-44. 10.1227/01.NEU.0000337574.58662.E2

7. McGirt MJ, Eustacchio S, Varga P, Vilendecic M, Trummer M, Gorensek M, Ledic D, Carragee EJ: A prospective cohort study of close interval computed tomography and magnetic resonance imaging after primary lumbar discectomy: factors associated with recurrent disc herniation and disc height loss. Spine (Phila Pa 1976). 2009, 34:2044-51. 10.1097/BRS.0b013e3181b34a9a

8. Meredith DS, Huang RC, Nguyen J, Lyman S: Obesity increases the risk of recurrent herniated nucleus pulposus after lumbar microdiscectomy. Spine J. 2010, 10:575-80.

10.1016/j.spinee.2010.02.021

9. Moliterno JA, Knopman J, Parikh K, Cohan JN, Huang QD, Aaker GD, Grivoyannis AD, Patel AR, Härtl R, Boockvar JA: Results and risk factors for recurrence following single-level tubular lumbar microdiscectomy. J Neurosurg Spine. 2010, 12:680-86. 10.3171/2009.12.SPINE08843

10. Morgan-Hough CV, Jones PW, Eisenstein SM: Primary and revision lumbar discectomy. A 16year review from one centre. J Bone Joint Surg Br. 2003, 85:871-74.

11. Park JS, Choi SE, Cho TK, Kim SH, Rhee W, Kim WJ, Ha SI, Lim JH, Jang IT: Recurrence rate after herniotomy only versus discectomy in lumbar disc herniation. Korean J Spine. 2013, 10:227-31. 10.14245/kjs.2013.10.4.227

12. Quah C, Syme G, Swamy GN, Nanjayan S, Fowler A, Calthorpe D: Obesity and recurrent intervertebral disc prolapse after lumbar microdiscectomy. Ann R Coll Surg Engl. 2014, 96:14043. 10.1308/003588414X13814021676873

13. Reith C, Lausberg G: Risk factors of recurrent disc herniation . Neurosurg Rev. 1989, 12:147-50. 10.1007/BF01741489

14. Shimia M, Babaei-Ghazani A, Sadat BE, Habibi B, Habibzadeh A: Risk factors of recurrent lumbar disk herniation. Asian J Neurosurg. 2013, 8:93-96. 10.4103/1793-5482.116384

15. Shin BJ: Risk factors for recurrent lumbar disc herniations . Asian Spine J. 2014, 8:211-15. 10.4184/asj.2014.8.2.211

16. Teli M, Lovi A, Brayda-Bruno M, Zagra A, Corriero A, Giudici F, Minoia L: Higher risk of dural tears and recurrent herniation with lumbar micro-endoscopic discectomy. Eur Spine J. 2010, 19:443-50. 10.1007/s00586-010-1290-4

17. Yoo MW, Hyun SJ, Kim KJ, Jahng TA, Kim HJ: Does obesity make an influence on surgical outcomes following lumbar microdiscectomy?. Korean J Spine. 2014, 11:68-73.

10.14245/kjs.2014.11.2.68

18. Ozgen S, Naderi S, Ozek MM, Pamir MN: Findings and outcome of revision lumbar disc surgery. J Spinal Disord. 1999, 12:287-92.

19. Wang JC, Dailey AT, Mummaneni PV, Ghogawala Z, Resnick DK, Watters WC 3rd, Groff MW, Choudhri TF, Eck JC, Sharan A, Dhall SS, Kaiser MG: Guideline update for the performance of 
fusion procedures for degenerative disease of the lumbar spine. Part 8: lumbar fusion for disc herniation and radiculopathy. J Neurosurg Spine. 2014, 21:48-53. 10.3171/2014.4.SPINE14271

20. Mroz TE, Lubelski D, Williams SK, O'Rourke C, Obuchowski NA, Wang JC, Steinmetz MP, Melillo AJ, Benzel EC, Modic MT, Quencer RM: Differences in the surgical treatment of recurrent lumbar disc herniation among spine surgeons in the United States. Spine J. 2014, 14:2334-43. 10.1016/j.spinee.2014.01.037

21. Lequin MB, Verbaan D, Bouma GJ: Posterior lumbar interbody fusion with stand-alone Trabecular Metal cages for repeatedly recurrent lumbar disc herniation and back pain. J Neurosurg Spine. 2014, 20:617-22. 10.3171/2014.2.SPINE13548

22. Fu TS, Lai PL, Tsai TT, Niu CC, Chen LH, Chen WJ: Long-term results of disc excision for recurrent lumbar disc herniation with or without posterolateral fusion. Spine (Phila Pa 1976). 2005, 30:2830-34. 10.1097/01.brs.0000190393.15369.94

23. Shin KH, Chang HG, Rhee NK, Lim KS: Revisional percutaneous full endoscopic disc surgery for recurrent herniation of previous open lumbar discectomy. Asian Spine J. 2011, 5:1-9. 10.4184/asj.2011.5.1.1

24. Ambrossi GL, McGirt MJ, Sciubba DM, Witham TF, Wolinsky JP, Gokaslan ZL, Long DM: Recurrent lumbar disc herniation after single-level lumbar discectomy: incidence and health care cost analysis. Neurosurgery. 2009, 65:574-78. 10.1227/01.NEU.0000350224.36213.F9

25. Schardt C, Adams MB, Owens T, Keitz S, Fontelo P: Utilization of the PICO framework to improve searching PubMed for clinical questions. BMC Med Inform Decis Mak. 2007, 7:16. 10.1186/1472-6947-7-16

26. Huang X, Lin J, Demner-Fushman D: Evaluation of PICO as a knowledge representation for clinical questions. AMIA Annu Symp Proc. 2006, 359-63.

27. El Shazly AA, El Wardany MA, Morsi AM: Recurrent lumbar disc herniation: A prospective comparative study of three surgical management procedures. Asian J Neurosurg. 2013, 8:139-46. 10.4103/1793-5482.121685

28. Dai LY, Zhou Q, Yao WF, Shen L: Recurrent lumbar disc herniation after discectomy: outcome of repeat discectomy. Surg Neurol. 2005, 64:226-31.

29. Guo JJ, Yang H, Tang T: Long-term outcomes of the revision open lumbar discectomy by fenestration: A follow-up study of more than 10 years. Int Orthop. 2009, 33:1341-45. 10.1007/s00264-008-0648-2

30. Ahsan K, Najmus-Sakeb, Hossain A, Khan SI, Awwal MA: Discectomy for primary and recurrent prolapse of lumbar intervertebral discs. J Orthop Surg (Hong Kong). 2012, 20:7-10.

31. Herron L: Recurrent lumbar disc herniation: results of repeat laminectomy and discectomy . J Spinal Disord. 1994, 7:161-66.

32. Palma L, Carangelo B, Muzii VF, Mariottini A, Zalaffi A, Capitani S: Microsurgery for recurrent lumbar disk herniation at the same level and side: do patients fare worse? Experience with 95 consecutive cases. Surg Neurol. 2008, 70:619-21.

33. Ahn Y, Lee SH, Park WM, Lee HY, Shin SW, Kang HY: Percutaneous endoscopic lumbar discectomy for recurrent disc herniation: surgical technique, outcome, and prognostic factors of 43 consecutive cases. Spine (Phila Pa 1976). 2004, 29:E326-32.

34. Cinotti G, Roysam GS, Eisenstein SM, Postacchini F: Ipsilateral recurrent lumbar disc herniation. A prospective, controlled study. J Bone Joint Surg Br. 1998, 80:825-32.

35. Hoogland T, van den Brekel-Dijkstra K, Schubert M, Miklitz B: Endoscopic transforaminal discectomy for recurrent lumbar disc herniation: a prospective, cohort evaluation of 262 consecutive cases. Spine (Phila Pa 1976). 2008, 33:973-78. 10.1097/BRS.0b013e31816c8ade

36. Kaner T, Sasani M, Oktenoglu T, Aydin AL, Ozer AF: Minimum two-year follow-up of cases with recurrent disc herniation treated with microdiscectomy and posterior dynamic transpedicular stabilisation. Open Orthop J. 2010, 4:120-25. 10.2174/1874325001004010120

37. Kim JS, Oh HS, Lee SH: Usefulness of carbon dioxide laser for recurrent lumbar disc herniation . Photomed Laser Surg. 2012, 30:568-72. 10.1089/pho.2012.3288

38. Kim KT, Park SW, Kim YB: Disc height and segmental motion as risk factors for recurrent lumbar disc herniation. Spine (Phila Pa 1976). 2009, 34:2674-78. 10.1097/BRS.0b013e3181b4aaac

39. Lee DY, Shim CS, Ahn Y, Choi YG, Kim HJ, Lee SH: Comparison of percutaneous endoscopic lumbar discectomy and open lumbar microdiscectomy for recurrent disc herniation. J Korean Neurosurg Soc. 2009, 46:515-21. 10.3340/jkns.2009.46.6.515

40. Silvers HR, Lewis PJ, Asch HL, Clabeaux DE: Lumbar diskectomy for recurrent disk herniation . J Spinal Disord. 1994, 7:408-19.

41. Niu CC, Chen LH, Lai PL, Fu TS, Chen WJ: Single cylindrical threaded cage used in recurrent 
lumbar disc herniation. J Spinal Disord Tech. 2005, 18:S65-72.

10.1097/01.bsd.0000128346.40145.b3

42. Huang KF, Chen TY: Clinical results of a single central interbody fusion cage and transpedicle screws fixation for recurrent herniated lumbar disc and low-grade spondylolisthesis. Chang Gung Med J. 2003, 26:170-77.

43. Niesche M, Juratli TA, Sitoci KH, Neidel J, Daubner D, Schackert G, Leimert M: Percutaneous pedicle screw and rod fixation with TLIF in a series of 14 patients with recurrent lumbar disc herniation. Clin Neurol Neurosurg. 2014, 124:25-31. 10.1016/j.clineuro.2014.06.020

44. Cheng J, Wang H, Zheng W, Li C, Wang J, Zhang Z, Huang B, Zhou Y: Reoperation after lumbar disc surgery in two hundred and seven patients. Int Orthop. 2013, 37:1511-17. 10.1007/s00264013-1925-2

45. Suk KS, Lee HM, Moon SH, Kim NH: Recurrent lumbar disc herniation: results of operative management. Spine (Phila Pa 1976). 2001, 26:672-76. 10.1097/00007632-200103150-00024

46. Hou T, Zhou Q, Dai F, Luo F, He Q, Zhang J, Xu J: Repeated microendoscopic discectomy for recurrent lumbar disk herniation. Clinics (Sao Paulo). 2015, 70:120-25.

10.6061/clinics/2015(02)09

47. Omidi-Kashani F, Ghayem Hasankhani E, Noroozi HR: Instrumented transforaminal lumbar interbody fusion in surgical treatment of recurrent disc herniation. Med J Islam Repub Iran. 2014, 28:124.

48. Li Z, Tang J, Hou S, Ren D, Li L, Lu X, Hou T: Four-year follow-up results of transforaminal lumbar interbody fusion as revision surgery for recurrent lumbar disc herniation after conventional discectomy. J Clin Neurosci. 2015, 22:331-37. 10.1016/j.jocn.2014.06.098

49. Chen Z, Zhao J, Liu A, Yuan J, Li Z: Surgical treatment of recurrent lumbar disc herniation by transforaminal lumbar interbody fusion. Int Orthop. 2009, 33:197-201. 10.1007/s00264-0080531-1

50. Parker SL, McGirt MJ, Coric D, Kim PK, Cahill KS, Devin CJ, Asher A: Arthrodesis vs revision discectomy for recurrent lumbar disc herniation: Patient-reported outcomes in 417 patients from the N2QOD registry. Spine J. 2015, 15:S101. 10.1016/j.spinee.2015.07.049

51. Lebow RL, Adogwa O, Parker SL, Sharma A, Cheng J, McGirt MJ: Asymptomatic same-site recurrent disc herniation after lumbar discectomy: results of a prospective longitudinal study with 2-year serial imaging. Spine (Phila Pa 1976). 2011, 36:2147-51. 10.1097/BRS.0b013e3182054595

52. Vik A, Zwart JA, Hulleberg G, Nygaard OP: Eight year outcome after surgery for lumbar disc herniation: a comparison of reoperated and not reoperated patients. Acta Neurochir (Wien). 2001, 143:607-10. 10.1007/s007010170066

53. Ebeling U, Kalbarcyk H, Reulen HJ: Microsurgical reoperation following lumbar disc surgery. Timing, surgical findings, and outcome in 92 patients. J Neurosurg. 1989, 70:397-404. 10.3171/jns.1989.70.3.0397

54. Fandiño J, Botana C, Viladrich A, Gomez-Bueno J: Reoperation after lumbar disc surgery: results in 130 cases. Acta Neurochir (Wien). 1993, 122:102-4. 10.1007/BF01446994

55. Kayaoglu CR, Calikoğlu C, Binler S: Re-operation after lumbar disc surgery: results in 85 cases . J Int Med Res. 2003, 31:318-23. 10.1177/147323000303100410

56. Paus B, Skalpe IO: The recurrence of pain following operation for herniated lumbar disc: fresh herniation or extradural scar tissue?. Int Orthop. 1979, 3:133-36.

57. Sotiropoulos S, Chafetz NI, Lang P, Winkler M, Morris JM, Weinstein PR, Genant HK: Differentiation between postoperative scar and recurrent disk herniation: prospective comparison of MR, CT, and contrast-enhanced CT. AJNR Am J Neuroradiol. 1989, 10:639-43. 